\title{
Operários da Firma: Mundo do Trabalho no Mundo do Crime
}

\author{
World of Labor, World of Crime
}

\section{Diogo Lyra}

Instituto Universitário de Pesquisas do Rio de Janeiro, Rio de Janeiro, Brasil

\section{RESUMO}

O objetivo desse artigo é explorar as dimensões simbólicas de um mercado de trabalho bastante singular, as práticas que o constituem são penalmente tipificadas como tráfico de drogas. Entretanto, para um grupo restrito de garotos pobres, essas atividades também são percebidas como âmbitos laborais e, portanto, dotadas de alguma legitimidade. O interesse do artigo é problematizar o tema das fronteiras entre o legal e o ilegal, em especial a relação entre tráfico e trabalho, a partir de uma reflexão sobre as narrativas de alguns jovens traficantes do Rio de Janeiro.

Palavras-chave: Juventude, Tráfico de drogas, Trabalho.

\section{ABSTRACT}

The purpose of this article is to explore the symbolic dimensions of a very unique job market, the practices that constitute it is penalized as drug trafficking. However, for a restricted group of poor boys, these activities are also perceived as working areas and, therefore, endowed with some legitimacy. The interest of this article is to problematize the theme of the boundaries between the legal and the illegal from this point of view.

Keywords: Youth, Drug trafficking, Labor. 


\section{INTRODUÇÃO}

"Aí eu falei pra ela que eu sou comerciante", me explicou Caxumba, vapor na favela de Antares, ao me contar a conversa que teve com sua namorada no dia em que a conheceu. Apesar do tom de galhofa com que me narrou o fato, a concepção do tráfico de drogas como uma forma de trabalho não é um mero eufemismo. Quando Caxumba ainda era um menino de sete anos, em meados de 1999, a Organização Internacional do Trabalho (OIT) publicou a Convenção 182, que trata da Proibição das Piores Formas de Trabalho Infantil, e a Recomendação 190, que estabelece a Ação Imediata para sua Eliminação. Entre as atividades, listadas taxativamente pela OIT, se encontra "a utilização, recrutamento e oferta de adolescente para outras atividades ilícitas, particularmente para a produção e tráfico de drogas".

Na qualidade de Estado signatário, o governo brasileiro promulgou a Convenção 182 no ano seguinte, com o Decreto 3597/2000, e instituiu a lista das piores formas de trabalho infantil quase uma década depois, com o Decreto 6481/2008 - que reproduz o referido trecho sobre o tráfico de drogas no inciso III do seu $4^{\circ}$ artigo. Ainda que, de uma perspectiva formal, essa legislação se encontre em pleno vigor no Brasil, no que tange à sua aplicabilidade ela é praticamente nula, pois juízes e promotores públicos, com algumas exceções, não reconhecem nas atividades do tráfico uma relação de trabalho (CABISTANI, 2017, p. 60).

Embora o tema não seja novo no mundo do direito, algumas pesquisas recentes do Galdeano (2018), em São Paulo, e de Napolião, Menezes, Lyra (2020), no Rio de Janeiro, trouxeram novo fôlego para o debate, procurando oferecer, com o aporte das Ciências Sociais, subsídios empíricos para uma mudança na práxis jurídica. Nesse sentido, as duas pesquisas estabelecem similaridades entre o legal e o ilegal, com ênfase na especialização das funções no tráfico, suas jornadas de trabalho, condições de assalariamento, entre outras correspondências diretas que iluminam e alinhavam atividades aparentemente díspares.

Sem deixar de recorrer a esses elementos, mas desinteressado em elaborar adequações ao universo jurídico, proponho aqui uma ampliação de referenciais, explorando dimensões mais subjetivas que interpelam o mundo do trabalho sob o enquadramento específico de jovens assalariados do mercado varejista de drogas. Para realizar esse empreendimento, divido este artigo em três partes. Na primeira, exploro a organização do trabalho nas firmas, mais especificamente suas atividades menos prestigiadas e de menor retorno financeiro, como a de olheiro e vapor, ocupadas pelos mais jovens. Em seguida, analiso as tensões, ambiguidades e aproximações das categorias "trabalhador" e "bandido" presentes nas reflexões de sociólogos 
e antropólogos nas últimas décadas. Por fim, problematizo a ideia de ruptura entre tráfico e trabalho, e demonstro como os trânsitos por essas esferas se explica mais por uma ideia de expansão/retração de horizontes que propriamente um cruzamento de fronteira ${ }^{1}$.

\section{A FIRMA}

Para se compreender a inserção dos garotos de favela no comércio de drogas, é preciso antes esclarecer que o "tráfico" possui, tal qual proposto por Barbosa (2006), uma "forma-Estado", que remete às formas de ingerência na vida coletiva e no âmbito de sua hierarquia interna, mas também "[...] possui um caráter empresarial, a firma - como é chamado o grupo de traficantes (por eles próprios) em nível local” (BARBOSA, 2006, p. 129). As firmas, na maioria dos centros urbanos, se estruturam de maneira muito similar, orientadas quase sempre conforme um "modelo empresarial" de distribuição e logística (JOHNSON et al, 1992). No modelo carioca, existe uma série de subdivisões de tarefas e funções que vão desde a administração dos radinhos e dos fogos de artifício até o verdadeiro "patrão" que centraliza os lucros fora da favela, em liberdade ou mesmo preso.

Para cada pequena função existe um trabalhador especializado que executa a tarefa. Evidente que isso depende da estrutura da firma, quanto maior for seu rendimento e demanda, mais a empresa tende a fracionar os campos de trabalho e especializar seus funcionários. Nos empreendimentos mais humildes é provável que um mesmo indivíduo realize diversas tarefas, como o empacotamento, a proteção e a venda. Obviamente, esta não é uma regra das firmas em si, mas uma característica do próprio mundo empresarial. Se o crescimento da firma exige a especialização de seus funcionários, é igualmente necessário que exista um coordenador responsável por cada uma dessas áreas, tarefa que é executada por inúmeros gerentes. A divisão do trabalho em gerências não se limita, portanto, a um posto central de coordenação, mas também se estende aos tipos de mercadorias (maconha, cocaína, crack) e aos valores/quantidade de cada porção. Assim, existe um gerente da maconha, por exemplo (gerente de carga), mas também

1 Todos os diálogos foram retirados de entrevistas que fiz com jovens em conflito com a lei ao longo dos últimos dez anos. As pesquisas foram realizadas no CRIAAD de Nova Iguaçu, durante minha pesquisa de doutorado no IUPERJ, entre 2008 e 2009, com financiamento do CNPq, nas unidades de internação da Capital, entre 2013 e 2014, em pós-doutorado pelo Social Science Research Council, com financiamento da Open Society Foundation; e nessas mesmasunidades da capital, em 2019, como pesquisador do CESeC, com recursos da Open Society Foundation. 
"subgerentes" das maconhas de dois reais, cinco reais, dez reais e etc. (gerentes de preço) - o mesmo acontecendo para cada um dos produtos, equipamentos - como rádios e armas - e até processos de empacotamento das drogas (BARBOSA, 1998; HIRATA, 2010; MALVASI, 2012; LYRA, 2013; GRILLO, 2013; BATISTA, 2014).

A firma disponibiliza aos seus funcionários um arremedo de plano de carreira baseado em uma ideia difusa de meritocracia. Os critérios de ascensão, no entanto, são menos racionais que o que termo pode sugerir, constituindo "dádivas" que, conforme demonstra Grillo (2013), são distribuídas a partir de parâmetros de consideração e apreço pessoal.

Proponho pensar o funcionamento da firma como um sistema de distribuição de propriedades e responsabilidades. Assim como a favela, também as bocas de fumo e os diferentes preços ou cargas de cada droga comercializada "pertencem" a um dono e são administrados por um responsável ou gerente. A princípio, todas as bocas e cada preço nelas vendido são de propriedade do dono, que distribui diferentes responsabilidades entre bandidos considerados, que passam a compartilhar dos lucros das bocas ou preços que eles forem designados para olhar, isto é, gerir. $\mathrm{O}$ ato de dar a um bandido uma responsa - como são chamadas essas responsabilidades - consiste em uma dádiva: uma concessão voluntária e aparentemente gratuita dos direitos de exploração comercial de áreas, pontos comerciais ou cargas de drogas vendidas a um determinado preço. Esta concessão é interpretada como a atitude de deixar forte ou dar uma condição, ou seja, de oferecer a alguém uma possibilidade de enriquecimento e ascensão hierárquica. Este dom expressa o apreço e consideração que o patrão nutre com relação aos seus funcionários, elevandoos a uma posição mais próxima à de sócio (GRILLO, 2013, p. 71).

A ideia de "crescer" no tráfico, por meio de demonstrações de lealdade, bravura e sacrifício, é um componente central no comportamento dos integrantes mais novos, que são remunerados nos cargos de menor prestígio e rendimentos, enquadrados por eles como o início de uma "caminhada" que, um dia, o levará a conquistar seu lugar ao sol. Ainda conforme Grillo (2013):

Ganhar uma condição deste tipo é o sonho alimentado por todos os jovens bandidos que entram para a boca, almejando sempre a chegada do dia em que serão reconhecidos por sua árdua dedicação à firma e presenteados com um cargo, podendo finalmente, ficar de patrão (GRILLO, 2013, p. 74).

Geralmente o jovem começa como olheiro - também chamado de radinho ou atividade - que são os postos mais baixos da firma, e que funcionam como uma espécie de estágio probatório. Existem diversas formas de ascensão na firma, mas em todas elas o que determina o crescimento de seus funcionários é o grau de confiança que despertam nos seus superiores. Chegar no horário, desempenhar bem sua função, não consumir o produto, ser corajoso, além de 
uma boa relação com os companheiros de trabalho, são fatores que tornam um jovem confiável e apto para assumir um cargo tão logo a empresa cresça, um funcionário faleça ou seja preso. Este sistema "meritocrático" do tráfico é de fundamental importância para o jovem. A oportunidade de crescer no trabalho, por meio de sua própria dedicação, em virtude de seus méritos e aptidões pessoais, propicia um reconhecimento social e uma satisfação individual que, no seu caso particular, dificilmente pode ser encontrada em um emprego convencional.

Para o jovem Salsinha, que vendeu bala no trem dos oito anos aos dez anos, e dos onze anos aos treze anos foi ajudante de pedreiro, a atividade no tráfico de drogas possibilitou uma sensação de crescimento profissional vedada, até então, às estratégias de reprodução material adotadas anteriormente.

P: Você começou trabalhando de vapor?

R: Não, foi de fogueteiro mesmo. Comecei segurando fogos. Aí depois já comecei segurando fogos, radinho, de vez em quando vinha um e deixava uma doze comigo...

P: Aí você ia ficando sagaz e os malucos...

R: Isso, eles ia botando pra crescer. Nisso até quando os maluco viu eu andando de pistola começaram a falar "pô aí, tu cresceu"! Porque geralmente o cara na favela só cresce quando ele é bom. Se o cara não for bom ele continua no mesmo estatuto que tá ali (Salsinha, 17 anos).

Como qualquer empresa que conhecemos, a firma exige de seus funcionários um rígido padrão de conduta durante o horário de trabalho. O jovem deve estar concentrado na sua atividade e não pode jamais desviar ou nublar sua atenção seja pelo cansaço, seja pela falta de seriedade. A desobediência dessas regras implica em penalidades que variam conforme a gravidade da infração, podendo se limitar a uma multa ou chegar a algumas "madeiradas". Nas faltas gravíssimas, o funcionário também pode ser afastado ou expulso da firma, do morro ou da vida. Ele também está impedido de consumir ou derramar sua mercadoria, mas é permitido o uso de drogas compradas com o dinheiro do jovem ou o consumo da porção que ele geralmente recebe da própria empresa para sua atividade diária.

Nesse sentido, existem algumas considerações interessantes. Substâncias como a maconha e a cocaína têm seu uso liberado, pois não se considera que exerçam prejuízo ao trabalho dos operários da firma. Pelo contrário, elas cumprem um importante papel na atividade diária do jovem, que consome a maconha para relaxar e a cocaína para ficar desperto. Geralmente à primeira é reservado o dia, enquanto a segunda é mais utilizada durante o pernoite do jovem em seu plantão. Porém, quando o assunto é o crack, existe uma profunda preocupação quanto ao uso, especialmente durante o horário de trabalho. Devido ao seu poder viciante, o consumo do 
crack é proibido a fim de evitar que o jovem utilize o estoque da firma, o que é imperdoável se ele não dispõe de recursos para saldar a dívida. Mesmo quando o estoque é particular e foi comprado pelo próprio funcionário, seu consumo pode gerar sérios problemas que comprometem a segurança dos outros jovens. Nas palavras de Marreco, que começou a ganhar a vida como catador de latinha aos dez anos, emendou na carreira de engraxate entre onze anos e doze anos, culminando numa rápida passagem por um lava-jato antes de entrar para a firma aos quatorze anos:

P: Na boca tinha gente que usava crack?

R: Ainda tem.

P: E qual era o proceder deles?

R: Não pode usar. Porque se usar paga multa de um galo. Se fizer de novo já toma uma madeirada. Porque se ficar deixando vai se ferrar mais tarde. E quem se prejudica mesmo é os cara lá (Marreco, 15 anos).

A rotina dos garotos do morro, em muitos sentidos, é plenamente equiparável ao mundo do trabalho convencional. Trabalhadores da firma e trabalhadores comuns acordam cedo, dirigem-se ao local de trabalho, param no intervalo do almoço, continuam trabalhando até retornarem para o lar, já tarde da noite, e tudo isso por um rendimento mensal que gira em torno de um a três salários mínimos. Com os ganhos de seu labor, sustentam a casa, os filhos, reforçam a renda dos pais humildes, festejam e adquirem alguns pequenos bens, nem sempre custosos, mas de alto valor simbólico para suas vidas. A sucinta descrição de Jacaré sobre seu cotidiano na firma não difere muito, no seu próprio ponto de vista, dos tempos em que, com apenas nove anos, guardava carros no centro de Caxias para completar a renda familiar:

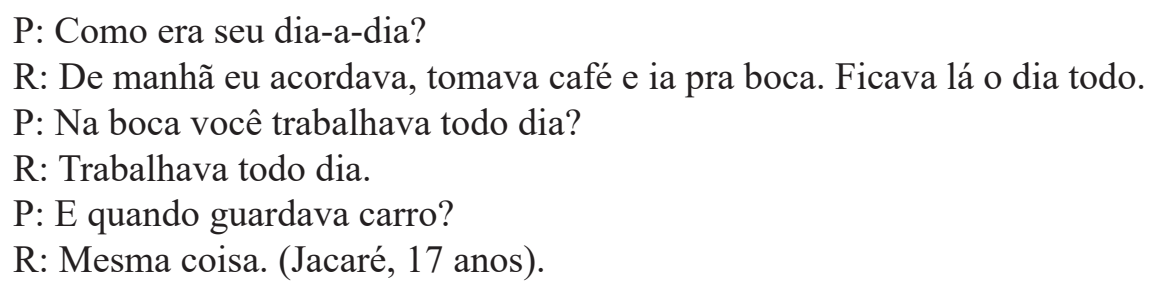

De certa forma, são poucos os elementos que possam diferenciar a rotina do assalariado do firma daquela estudada por Alba Zaluar quando analisou, nos idos dos anos 80, o trabalhador pobre da Cidade de Deus. Para a antropóloga, não havia entre eles uma "ética do trabalho" nos moldes clássicos instituídos pelo protestantismo, em que o trabalho é um valor em si, mas uma "ética do provedor", cuja única fonte de satisfação moral e material do chefe de família consistiria nos bens que ele pode comprar (ZALUAR, 1985, p. 121). Apesar da extravagância de alguns jovens, boa parte dos entrevistados dificilmente gastava seu dinheiro em situações 
que iam além do sustento de seu núcleo familiar, a compra de alguns objetos valorizados em sua vida social e do lazer nas agitadas noites de baile. Berlota, ex-ajudante de pedreiro, ex-ensacolador, ex-catador de papelão, ex-ambulante, ex-lavajatista e ex-auxiliar de cozinha, sempre cuidou dos irmãos, na ausência do pai assassinado e da mãe presidiária.

P: Com o dinheiro que você ganhava traficando você gastava em quê?

R: Algumas eu dava um dinheirinho pros meus irmãozinho se divertir na rua, comprava umas roupa pra mim, pra eles... (Berlota, 18 anos).

Submetido a baixos ganhos salariais, à sujeição patronal, carga horária fixa e rigidez de compromisso, os garotos do tráfico se assemelham mais à imagem de operários que à de um "novo rico" da favela, fruindo uma vida de luxo e ostentação, como notamos nesta análise:

Após a gradual conversão aos valores da violência e da nova organização criminosa montada no uso constante da arma de fogo, esse jovem descobre os prazeres da vida de rico e com este se identifica. Seu consumo passa a ser uma cópia exagerada, orgiástica do que entende ser o luxo do rico: muita roupa, carros, mulheres, uísque (bebida de "bacana") e muita cocaína (coisa de gente fina) (ZALUAR, 2004, p. 65).

Esse "perfil”, embora não seja de todo absurdo, não se confirma para a imensa maioria dos moleques mal vestidos, angustiados, cercados de filhos e familiares necessitados, arriscando sua vida por dez reais a hora (NAPOLIÃO; MENEZES; LYRA, 2020). De fato, a firma é um posto de trabalho e é dessa maneira que muitos jovens a encaram. No depoimento a seguir, o garoto Naldinho, que aos quatorze anos desistiu de carregar entulho para trabalhar como fogueteiro na firma, apresenta um percurso descendente na hierarquia do tráfico, trocando a atividade de olheiro pela de entregador de quentinha. Para ele, os riscos não valiam a pena:

P: Aí lá na boca você passou a trabalhar com mais alguma coisa?

$R$ : Entregador de quentinha.

P: Então de fogueteiro você foi pra entregador de quentinha? Você pediu pra mudar?

R: Pedi pra mudar.

P: Por quê?

R: Porque o entregador de quentinha só entregava quentinha, de manhã, na hora do almoço, entregava o café de manhã...

$\mathrm{P}$ : E você tirava quanto?

$\mathrm{R}$ : Tirava menos, tirava 90 reais, 10 reais a menos.

P: Mas você achou mais vantagem mudar por que trabalhava menos ou por que era mais risco?

$\mathrm{R}$ : Porque era menos risco, porque entregador só entregava quentinha e depois não fazia mais nada (Naldinho, 15 anos). 
O fato de serem trabalhadores assalariados, com rendimento fixo, no caso dos olheiros, ou com ganhos comissionados, no caso dos vapores, desperta, entre alguns jovens ladrões, a ideia de que as atividades ligadas ao comércio local de drogas constituem uma reprodução das relações desiguais de trabalho na polis, e são apresentadas sob a perspectiva da exploração e da produção de riqueza para o patrão. Para Cenoura, que trabalhava em um bar de dia, estudava de noite em um colégio municipal em Nova Iguaçu, e nos fins de semana roubava em Copacabana, traficar é "fazer dinheiro pros outros".

P: E por que você disse que traficar é fazer dinheiro pros outro?

R: Porque os cara tão lá fazendo dinheiro pros outros mesmo, o único que tá botando a mão no bolso é o patrão mesmo (Cenoura, 18 anos).

Além disso, para os autônomos do 157, como defini os ladrões noutra oportunidade (LYRA, 2013), não só a sujeição patronal estabelecida entre o dono do morro e os jovens assalariados da firma denota esta falta de liberdade. Também os próprios limites do tempo e do espaço impostos aos traficantes, isto é, o cumprimento da jornada de trabalho em um ponto fixo, na boca-de-fumo, contribui para que os ladrões se sintam mais independentes e seguros na sua atividade. Para eles, o fato de andarem livremente pela cidade é uma vantagem, sobretudo se comparado à rotina imposta aos colegas do tráfico, mais vulneráveis às investidas da polícia, tornando o custo-benefício desta atividade menos atraente. Na avaliação de Etiópia, que já começou a vida roubando transeuntes no centro de Belford Roxo aos treze anos, os ganhos no tráfico não compensam os riscos que a atividade impõe:

P: Você nunca pensou em entrar (para a boca)?

R: Não, ali você tá arriscando sua vida e não ganha porra nenhuma. Você sai pra roubar, o que você vai roubar num dia não ganha numa semana lá. Você tá lá traficando, aí chega a polícia dentro, tira sua vida a qualquer hora. No roubo não (Etiópia, 16 anos).

\section{FORÇAS DE TRABALHO}

A tensão entre "trabalhadores" e "bandidos" aparece como um dos elementos fundantes das reflexões sobre violência no Rio de Janeiro, em especial no que tange às análises sobre o tráfico de drogas. A Máquina e a Revolta, etnografia seminal de Alba Zaluar, publicada em 1985, é, sem dúvidas, a obra mais representativa desse tipo de perspectiva. Embora tratados 
pela autora como elementos polares de uma mesma condição social de pobreza, Zaluar (1985) destaca que, mesmo se definindo como a antítese dos bandidos, os trabalhadores pobres da Cidade de Deus invocavam em seus testemunhos diferentes pontos de convergência moral entre um grupo e outro. Essas zonas de permeabilidade e trânsito eram alinhavadas pelos moradores a partir de predicados como vizinhança, proteção e assistência, atribuídos aos bandidos em certas circunstâncias.

\begin{abstract}
A identidade de trabalhador constrói-se em parte por oposição a bandidos e vagabundos que não trabalham. Mas se o trabalho é um critério fundamental de diferenciação entre tais categorias, isso não quer dizer que a oposição entre eles seja rígida e absoluta ou que exista, no plano das relações sociais, uma segregação claramente demarcada, separando-os completamente. Ao contrário, as relações entre bandidos e trabalhadores mostram-se muito mais complexas e ambíguas, tanto no plano das representações que a atividade criminosa tem para os trabalhadores, como no plano das práticas efetivamente desenvolvidas entre eles (ZALAUR, 1985, p. 132).
\end{abstract}

É notável como a presença dessa ambiguidade discursiva que ora antagoniza, ora aproxima trabalhadores e bandidos, se estende ao longo das décadas seguintes, como podemos observar nas entrevistas que Márcia Leite (2005) e Machado da Silva (2008) conduziram com moradores de favelas no Rio de Janeiro vinte anos depois de Alba Zaluar (1985). Nos grupos focais e entrevistas individuais com cerca de 150 residentes de favelas não envolvidos com o crime, a oposição entre "trabalhadores" e "bandidos" emergiu como a forma de classificação basilar que delimitaria, em suas falas, uma fronteira explícita entre tais grupos. Contudo, a rigidez dessa oposição perdia força em certos momentos, quando então, na fala dos moradores, eram citados laços de pertencimento que os aproximavam social e moralmente dos traficantes. Nesses casos, a atividade criminosa era substituída pela identidade da vizinhança, fundamentada no compartilhamento de experiências locais, próprias daqueles que cresceram juntos, conforme destacado pelos autores em depoimentos como o que segue abaixo,

Antes de ser bandido, ele é morador. Antes de ser traficante de drogas, jogou bola comigo. Jogou bola comigo... virou bandido. Estudou com ela... virou bandido. Se o cara foi, chegou desarmado, sem nada, e quer tomar uma cerveja, você vai conversar com ele. Agora, você não vai ficar participando do que ele participa, você não vai cheirar, fumar, assaltar com ele. (MACHADO DA SILVA, 2008, p. 128).

Muitos dos pais e mães entrevistados por Zaluar em 1985 já eram avós ou mesmo bisavós na segunda metade dos anos 2000, quando a pesquisa de Leite (2005) e Machado da Silva 
(2008) foi conduzida. Da mesma forma, muitos dos filhos de moradores entrevistados por esses dois pesquisadores hoje também são pais. Tomando o núcleo familiar como marcador de tempo, temos de três a quatro gerações socializadas sob a vigência do tráfico de drogas enquanto ente "animador" da vida coletiva nas favelas. Nesse lastro temporal, como aponta Gabriel Feltran (2007) em Trabalhadores e Bandidos, as relações de atração e repulsa entre esses grupos se reconfiguram de forma avassaladora.

Ao reconstituir a trajetória de Ivete, nordestina, mãe de família, que chegou a São Paulo na segunda metade dos anos 80 e criou oito filhos na periferia de Sapopemba, somos conduzidos a um ponto de inflexão determinante. Ao longo dos anos 2000, durante o trabalho de campo de Feltran, cinco dos seus filhos já tinham sido presos em diferentes ocasiões. O crime, antes agente externo, estranho, agora adentra as portas da casa, se mistura à família, e adensa as zonas de permeabilidade, quase as normalizando. A Sapopemba estudada por Feltran (2007) emerge como o cenário mais radical de diluição das fronteiras entre mundos antes tomados como absolutamente distintos.

A narrativa de Ivete, então, não tinha nada a ver com as narrativas das famílias "trabalhadoras" das periferias, sempre centradas numa trajetória linear que gravita em torno do trabalho (ou das tentativas de consegui-lo), e da oposição radical entre o trabalho e o crime. Eu estava acostumado a esta narrativa bipolar, em que violência e crime apareciam como entes indesejados no seio da família, e, no entanto, na forma de Ivete estruturar seu depoimento, a criminalidade aparecia como dimensão constitutiva das atividades e das rotinas da família Naquela família, portanto, a demarcação da moral familiar e do que seria desviante, com relação a ela, não era clara. Não se distinguia ali, com nitidez, a linha que separava a família, e seus valores, daqueles vividos no mundo social ou no mundo do crime. Era como se a família tivesse sido tomada por estes mundos, que passavam a ditar seu ordenamento (FELTRAN, 2007, p. 6).

O mundo regido por fábricas, sindicatos, paróquias, associações de moradores e escolas que Ivete já conheceu sob esfacelamento, sem no entanto deixar de herdar sua moralidade, se traduz como algo incognoscível para os jovens do presente. A interlocutora de Feltran (2007) transparece como o produto de sobreposições morais que, em algumas gerações, sedimentou a nova superfície onde os filhos dos seus filhos passeiam. O crime faz parte da família. E divide a moralidade da casa com os elementos tradicionais de outrora, marcados pelo suor, na figura dos seus outros filhos "honestos". A ética do provedor, antes um bastião da diferença que demarcava as virtudes dos trabalhadores no seio da vida familiar, mas também na vida pública - como apontado por Zaluar em 1985 - agora é incorporada pelos bandidos, cuja trajetória passa a ser expressa sob a chave da opção, uma escolha como outra qualquer e não mais como uma ruptu- 
ra.

No plano simbólico, são os filhos "trabalhadores" que sustentam a estrutura do grupo. São o orgulho da mãe. No plano material, entretanto, o sustento da casa é garantido pelos filhos "do crime". A família ganha provedores simbólicos e materiais, o que permite que se restabeleça. E assumida esta nova condição, a crise tende a passar (desde que nenhuma tragédia sobrevenha sobre ela, o que não é improvável). Entre o padrão discursivo daqueles depoimentos sobre a época das primeiras prisões dos filhos, que deixaram Ivete de cama, e o padrão encontrado nas últimas visitas, há um deslocamento evidente. No final de 2007, ela fazia até piada do vai e vem dos filhos: estou só querendo ver quem vai ser o próximo a ser hospedado pelo governador. A crise moral é controlada racionalmente, a condenação dos atos criminosos deixa de ser o centro da atenção. Trata-se de uma "opção" pela vida do crime, como outra qualquer. O crime ou o trabalho passam a ser uma escolha individual - e cada escolha leva a um conjunto de consequências, um estilo de vida etc. Todos conhecem os códigos de uma ou outra "opção", e ambas passam a caber dentro da família. A primeira garante mais claramente o sustento, mas torna a família vulnerável à polícia e às tragédias; a segunda é menos rentável, embora seja mais legitimamente aceita, no mundo social. (FELTRAN, 2007, p. 21).

Se, como aponta Feltran (2007), muitos trabalhadores, na intimidade dos seus lares, passaram a conviver com a moralidade do crime, procurando formas de regurgitá-la sob novos arranjos, também entre "bandidos", ao menos aqueles em início de carreira, como o são os jovens que pesquiso, vê-se os resultados dessa diluição de fronteiras. Algo do mundo do trabalho perturba os sonhos de independência indomável, de riqueza, de bravura heróica, idealizados pelos garotos que atualmente ingressam nas fileiras do tráfico.

Nas firmas os recrutas dos novos tempos encontram uma estrutura altamente especializada e diversa em suas funções. Nela ingressam como atividade, portando um radinho, por onde avisam outros parceiros acerca dos movimentos estranhos ou suspeitos no morro. É o posto mais baixo da firma e funciona como uma espécie de estágio probatório, que permite ou não sua promoção para vapor, isto é, como vendedor. Ambos trabalham em turnos de 12 horas por dia, recebendo em valor fixo, no caso dos atividades, ou por comissão, em se tratando dos vapores. Seus ganhos giram em torno de três salários mínimos. Estas são, também, as funções de maior exposição e risco frente a polícia. Não raro, aqueles que não são assassinados, duram um, dois, três meses no cargo até serem presos pela primeira vez. Muito embora guardem a expectativa de subir na vida, ganhando uma gerência ou mesmo se tornando, um dia, o frente do morro, quiçá o dono, a maioria desses garotos compreende que dão duro o dia inteiro para que outros se apropriem dos grandes lucros de seu comércio. O conceito de "bandido" se reformula e passa a expressar algo que eles ainda não são. As palavras de Russo, que dos onze anos aos 
quatorze anos alternou entre lavar carros e coletar materiais recicláveis, passando a carregar caixotes na CEASA de Irajá até entrar para o tráfico com dezesseis anos, demonstram bem essa perspectiva:

Que bandido, irmão?! Bandido é o cara que tá lá recebendo... com um montão de mulher, em frente à praia. Ele é o patrão e você tá se fudendo, botando a cara, entendeu? Então, "ah, eu sou bandido porque seguro o três oitão". Segura um três oitão, o cara chega e porta fuzil. O patrão chega, porta fuzil, todo mundo de fuzil em volta dele... e aí, que bandido é você? Arriscou sua vida, deu dinheiro pro cara, certo? E o cara com um montão de mulher. E tu na merda, ganhando cento e cinquenta, cem merréis por mês (Russo, 17 anos).

Um dos aspectos mais interessantes desse depoimento reside no fato de que a fala de Russo adquire ares de crítica ao sistema capitalista, desnudando a exploração do assalariado frente ao empresário. Enquanto o primeiro trabalha duro, o outro frui os lucros do negócio de frente para o mar, cercado de mulheres, alheio aos sacrifícios dos funcionários da firma. A despeito dessas aproximações, no entanto, a categoria "trabalho" não aparece entre os meninos do tráfico como um conceito adequado para descrever suas atividades.

Em Trabalhar e não ser trabalhador, Freitas e Costa (2018) apresentam a percepção paradoxal de adolescentes envolvidos com o tráfico de drogas no Espírito Santo acerca de sua condição peculiar. Estes, ao mesmo tempo em que afirmam "trabalharem no tráfico", e que tal atividade é fruto de suas necessidades elementares de reprodução material, se distanciam dos trabalhadores mobilizando questões morais, questões relativas aos valores recebidos por cada tipo de assalariado, suas formas de fruição e o caráter mais óbvio da tensão legal versus ilegal. Porém, compreendem o mundo dividido entre dois pólos: de um lado, os privilegiados, encarnados na figura do "playboy"; de outro, os despossuídos, onde se encaixam tanto "trabalhadores" quanto "bandidos".

Detecta-se aqui uma percepção da sociedade de classes a partir da perspectiva dos adolescentes, de forma que eles dividem a sociedade na qual vivem em três classes. Pode-se notar que "trabalhadores" e "vagabundos", apesar de serem classificações diferentes, são unidos por um fator em comum. Na percepção dos adolescentes, o que essas "classes" têm em comum é o que as oporia aos "playboys", portanto os "playboys" não teriam a preocupação imediata com a sobrevivência e com a satisfação das necessidades imediatas - sejam elas do estômago ou da fantasia. Logo, "trabalhadores" e "vagabundos" possuem necessidades que requerem respostas urgentes (FREITAS; COSTA, 2018, p. 944).

Uma das dificuldades em se averiguar a situação de "trabalhador" entre jovens do tráfico é o peso histórico e conceitual que o termo carrega. Dessa forma, qualquer tentativa de 
equiparação entre o trabalho em sentido estrito e as funções desempenhadas pelos adolescentes nas bocas de fumo não consegue ir além de uma espécie de analogia entre mundos distantes. Compreender a atividade de adolescentes pobres no tráfico de drogas como um trabalho implica, antes de tudo, compreender o mundo no qual ele está inserido, e que é ordenado em toda sua amplitude, nas mais diversas esferas, pela força gravitacional dessa mesma atividade. É o mundo onde esses jovens estão, e não suas atividades propriamente ditas, que precisa ser descrito para conferir a estas inteligibilidade e lugar. Ao empreender essa tarefa, se torna evidente, em parte, o entendimento da adesão de jovens ao tráfico de drogas não como uma ruptura em suas trajetórias particulares, de um lado, e frente ao ordenamento social, de outro, mas como uma das tantas escolhas possíveis na miríade de trabalhos precários disponíveis a essa geração específica.

\section{ANDAR JUNTO}

Observamos que, na fala de trabalhadores sobre bandidos, bem como de bandidos sobre trabalhadores, os pontos comuns assinalados são os mesmos e referem-se, basicamente, ao fato de se conhecerem, de dividirem um mesmo espaço e compartilharem, cada um a seu modo, uma vida de "sofrimento". Laços de amizade, vizinhança e, no limite, solidariedade, dissolvem, em um plano abstrato, as fronteiras que, de maneira mais objetiva, demarcam suas diferenças. É um deslocamento equivalente, embora menos abrangente, àquele que, segundo Adaton Marques (2014), define a categoria "correr com o crime". Para o autor, "correr com o crime" não se definiria propriamente pela distinção entre os que cometeram e os que não cometeram infrações penais, sendo, antes, um conjunto de códigos, relações e considerações.

Pode-se dizer que um cara "corre com o crime" sem necessariamente se tratar de um assaltante, de um traficante, de um sequestrador, inclusive se tratando de um trabalhador comum, desses que saem de casa às seis horas da manhã, enfrentando uma hora e meia de ônibus lotado, labutando durante todo dia, comendo marmita e sofrendo novamente no transporte público pra chegar em casa às vinte horas. Ele "não desmerece" os "ladrões" de sua "quebrada", toma cerveja com eles no "barzinho" - pagando com seu próprio dinheiro, fruto de trabalho - , divide com eles o campo de futebol de várzea da "vila", comemora com eles os mesmos aniversários, aguenta com eles "as geral da polícia”, sem caguetar quem tá no "movimento" (MARQUES, 2014, p. 164).

É muito comum que a adesão de um jovem favelado a um coletivo criminal seja interpretada pelo senso comum como ruptura, tanto em relação à ordem social, quanto no que tange 
à sua própria trajetória pessoal. Nesse sentido, figura, sob tal pano de fundo, a ideia de "entrar para o crime", pensada como um "ato" que substitui um mundo por outro. Embora admita que, sob certos ângulos, essa perspectiva seja válida, acredito que ela reduz nossas possibilidades de se compreender esta opção em sua dimensão estrutural, tratando-a não como o marco inicial de uma carreira criminal, mas como a culminação de um longo processo social. Processo este que é marcado pela continuidade no plano macro histórico, e pela contiguidade no âmbito da trajetória pessoal de um adolescente.

No primeiro caso, a continuidade é demarcada pela não integração desses territórios à cidade - onde, nas últimas quatro décadas, sedimentam-se as experiências de controle territorial promovidas pelo tráfico. Por outro lado, o plano da contiguidade se afirma pela onipresença dessa mesma estrutura nos mais diversos âmbitos de sua vida. Isso porque o tráfico de drogas, em sua "dimensão de Estado", submete trabalhadores e bandidos a um mesmo regime, ainda que com diferentes efeitos e repercussões, e se imiscui em cada poro, passo e pensamento daqueles que vivem nesses espaços segregados espacial e institucionalmente. Suas implicações influenciam ou determinam noções de justiça, honra, virtude e status (GRILLO, 2013; LYRA, 2013; FELTRAN, 2011; BIONDI, 2010); de mobilidade, território, identidade e lazer (NERI, 2011; BARBOSA, 1998); cria uma estética própria (ORTIZ, 2012; RINCÓN, 2013); define limites e condições para o amor (COSTA, 2008); transparece na religião (FACINA; PALOMBINI, 2016; CUNHA, 2008); incuti relações de admiração, amizade e antagonismo (HIRATA; GRILLO, 2017; MARQUES, 2014;), entre outros inúmeros elementos cotidianos que vão se tornando imperceptíveis, naturalizados, e que se cristalizam como uma "ordem social autôno$m a "$, com profundas implicações sobre a subjetividade daqueles que estão submetidos à sua influência (MACHADO DA SILVA, 2008).

Sob essa perspectiva apresento a categoria nativa andar junto como uma chave de interpretação cujo sentido poético e semântico encontra substância antropológica como descrição de "liminaridade", "trajetória" e "familiaridade". O depoimento de Marimba, que começou a fazer bico aos nove anos de idade, e desde então vendeu bala, engraxou sapato, guardou carro, foi ensacolador, ajudante de pedreiro e que, à época de sua "entrada" no tráfico, trabalhava em uma padaria, demonstra como esses elementos atuam:

P: Mas aí tu entrou como na boca?

$\mathrm{R}$ : Ah, eu já andava junto com eles desde menorzinho... jogava bola, fumava um baseado. Vários era amigo de escola, que a gente tocava o terror na escola, jogava bola, pá. Tinha vez que eles tava lá parado, aí pedia pra comprar comida, pra buscar um refrigerante, aí me dava um trocado. Aí um dia que os polícia tava lá embaixo, e eles tava tudo lá na rua, eu avisei “ó, os cana tão 
brotando"... No outro dia geral pá, "menor de consideração, não quer fechar com nóis”? Eu falei "já é” (Marimba, 16 anos).

Interessante notar como a noção de paulatino envolvimento que caracteriza o andar junto, e que pode culminar na adesão de um jovem favelado a um coletivo criminal, também pode descrever os processos de adesão ao trabalho formal tendo em vista os mesmos parâmetros de "liminaridade", "trajetória" e "familiaridade". No depoimento abaixo, Bira, morador da favela Gogó da Ema, em Belford Roxo, que desde sempre trabalhou no tráfico, utiliza a mesma linha de raciocínio de Marimba, baseada na noção de "envolvimento", para descrever um desfecho diametralmente oposto:

P: Essa galera da comunidade que faz curso, entra pro tráfico?

R: Não.

P: Por quê?

$\mathrm{R}$ : Porque tá construindo alguma coisa, tá distraindo a cabeça com outra coisa. Não tá ali só vendo o tráfico. Vai conversando e vai se envolvendo. (Bira, 16 anos).

Os depoimentos de Bira e Marimba são cruciais para a compreensão do andar junto como uma problema de "horizontes" mais que de "fronteiras", pois os processos que levam a um ou outro caminho são, a rigor, os mesmos: "vai conversando e vai se envolvendo". Contudo, se a noção de envolvimento paulatino é igualmente útil para descrever quem "entra para o tráfico" e quem entra no mercado de trabalho em sentido estrito, as implicações existenciais na vida daqueles que se tornam bandidos são avassaladoras, de tal forma que afetam, inclusive, suas dimensões de espaço e tempo.

P: Por que tem menor que entra e menor que não entra, se eles tão na mesma situação?

$\mathrm{R}$ : Porque tem uns que pensa mais pra frente e outros que pensa só no agora. Os que pensa no agora entra.

P: Você acha que trabalhador tira onda?

R: Trabalhador tira, mas tira onda no asfalto, né? Na favela quem tira onda é... as mulher, as mulher gosta dos cara que anda de peça. Se tiver na mão, se eu morar na favela e tu ficar com os moleque da boca, as mulher vai dar preferência a quem é da boca.

P: E por que o trabalhador tira onda no asfalto?

$\mathrm{R}$ : Ah, tira onda com as mulher do trabalho, as mulher certinha. Tira onda... aí casa, mora junto, tem filho. Aí tem um futuro. Na favela não, tem gente que tem futuro também, namora, pá, mas é pouco. Mas as mulher prefere os cara da boca. Aí morre, já tá com outro, e assim vai indo (Barriga, 15 anos). 
Barriga situa trabalhadores e bandidos em esferas existenciais distintas, não comparáveis, e elabora a ideia de "horizonte", subjacente à categoria andar junto, nos termos espaço-temporais a que aludi anteriormente. Para ele, que desde os doze anos dava duro entregando as quentinhas que a mãe preparava, o trabalhador se projeta para a cidade, cria relações sólidas, se estende existencialmente numa perspectiva de futuro, enquanto que, o bandido está limitado às demarcações territoriais da favela, preso no agora, e fadado à brevidade da finitude. Freitas e Costa (2018, p. 951), por exemplo, também notaram essas drásticas alterações existenciais quando examinaram a relação dos adolescentes com o dinheiro "[...] é de se admirar outro aparente paradoxo que eles me apresentavam: quando tinham altas rendas, não tinham qualquer excedente no final do mês; quando recebiam parcos salários, conseguiam economizar". Poupar ou gastar; o futuro ou o agora; são ações e noções relacionadas a outro tema levantado por Barriga - a morte - e que pode oferecer alguns insights sobre a inquietante e crucial diferença entre trabalho no tráfico e trabalho formal não problematizada até aqui, isto é, a possibilidade de matar e de morrer.

A morte, como um acontecimento breve, é um elemento que também costura "trabalhadores" e "bandidos", ainda que com intensidades diferentes. Envolvidos ou não, todos aqueles que moram ou se encontram na favela são obrigados a lidar com a morte quase que cotidianamente, seja em virtude das operações policiais, das tentativas de invasão por grupos rivais, ou mesmo em decorrência da ação do próprio grupo local de traficantes. De acordo com uma pesquisa de Napolião, Menezes, Lyra (2020, p. 17), 39\% dos adolescentes cumprindo medidas de internação na capital por tráfico de drogas afirmaram que tiveram algum parente assassinado, a maioria pela polícia. Muitos desses executados friamente ou atingidos no fogo cruzado da "guerra às drogas".

Embora os limites desse artigo me impeçam de analisar esse tema com a devida profundidade, estou seguro para afirmar que, nesse universo de horizonte restrito, onde a favela é o mundo, a relação com a morte enquanto um episódio cotidiano e visível impacta profundamente a maneira como seus moradores lidam com a vida. Em A metafísica da morte, Simmel argumenta que

Pode-se ver claramente a significação da morte como criadora de forma. Ela não se contenta com limitar nossa vida, quer dizer, dar-lhe forma à hora do desenlace; ao contrário, a morte é para a nossa vida um fator de forma, que vai matizar todos os seus conteúdos, fixando-lhe inclusive os limites (SIMMEL, 1999, p. 3).

Inquirido sobre o medo de morrer, Berlota, um adolescente de dezesseis anos, sumari- 
zou toda a dimensão sociológica arguída por Simmel (1999) em sua reflexão sobre a finitude: "morreu hoje, amanhã já faz dois dias". Isso não significa, no entanto, que o ato de matar ou o advento de morrer constituam banalidades na vida desses garotos. Mas sim que, nos limites da favela, ao longo de décadas e décadas, ela deixou de ser um infortúnio, passando a ser encarada como um elemento que, em última análise, é incorporado como parte da sua dinâmica social. Andar junto, nesse sentido, também abarca a possibilidade da morte, compartilhada por envolvidos e não envolvidos. Assim é a opinião de Jacaré, que fazia bico como assistente de pintor até se ver envolvido em uma perseguição policial em sua favela:

P: E como foi que tu entrou pra boca?

$\mathrm{R}$ : Pô, é que nós andava junto desde bebezinho... nesse dia a gente fumamo vários baseado, geral gastando, os polícia brotou, pow, pow, já sentando o dedo. Aí eu "caralho mané"! Saímo fora, um menor lá caiu [morreu]. De noite dei um papo no frente, e ele "já é". Aí eu "cadê minha arma"? (Jacaré, 17 anos).

São as formas de fruição da vida, e não propriamente a maneira como esse intento é atingido, que parecem estar no cerne das diferenças entre trabalhadores e bandidos, razão pela qual o crime pode ser entendido como uma opção de sustento sem suscitar grandes contradições morais entre os adolescentes. Por essa razão, defino a socialização pelo trabalho, entre esse grupo específico de jovens, como um movimento reiterado, mas nem sempre contínuo, de retração e ampliação de seus horizontes. Nesse universo de espaço-tempo comprimido, onde a favela é o mundo por si só, e onde o tempo corre rápido, os operários da firma trabalham seis dias por semana, em plantões de 12 horas por dia, com salário fixo semanal - no caso dos olheiros - ou ganhos por comissão - como acontece com os vapores. Sua renda varia entre um e três salários mínimos, renda com a qual dão conta de seus prazeres e necessidades, e se projetam na favela como indivíduos bem sucedidos, em carreira ascendente, auferindo também ganhos imateriais que vão do status social às relações amorosas. Mas existe um último elemento importante para se compreender, em parte, outra satisfação simbólica possibilitada pela firma e que a torna, para alguns, algo maior que uma forma de sustento.

Diversos trabalhos acerca da juventude apontam a centralidade dos grupos informais na construção da sua subjetividade, pois são nesses grupos que o jovem constrói suas primeiras redes simbólicas de interação de maneira autônoma e autoconsciente. Parsons (1968) aponta a importância do "grupo homogêneo", isto é, dos grupos formados fora do ambiente familiar e escolar, como lócus da aceitação não-adulta e da experimentação, muitas vezes reprovável, que prepara o jovem para o mundo social. Nestes contextos, preferencialmente quando o grupo 
é formado por indivíduos do sexo masculino, as interações entre seus membros constituem palcos de "aquisição e exibição do vigor" (PARSONS, 1968, p. 58), manobras cujo principal objetivo é granjear a admiração de outros indivíduos da mesma idade. Para autores como René Fau (1968, p. 46), o grupo de adolescentes é violento por natureza, mas também absorve a violência individual na medida em que representa uma personificação coletiva.

As repercussões da falta de um ambiente no qual esses encontros coletivos possam transcorrer de maneira construtiva, estimulando no jovem uma projeção de vida em sociedade, pode ser avaliada em estudos como o de Elias (2000) e seus jovens de Winston Parva, nas reflexões de David Matza (1964), sobre a deriva da juventude pobre americana, ou nos relatos de Foote-Whyte (2005) sobre os rapazes das esquinas de Corneville. Mas será que esse elemento gregário se aplicaria também ao tráfico ou esta atividade comportaria apenas as realizações pelo status e retorno financeiro? Como esta era uma questão que me intrigava, durante minhas entrevistas costumava perguntar aos garotos se a firma representava para eles um trabalho ou uma família. A palavra família, além do significado usual, é empregada sob a forma de gíria e sinaliza de uma relação de aliança, em um extremo, a uma relação de não-hostilidade no outro: "Que isso, família, pode vir sossegado" - foi a resposta de um dos garotos para um comprador que lhe perguntou se era tranquilo subir o morro. Admito que esse tipo de pergunta contém diversas imprecisões, mas assumi cautelosamente o risco.

P: Quando você tava lá plantando, era como se fosse um trabalho ou como se fosse uma família?

R: Uma família. Geral como, um do lado do outro. Ajudar o que der e vier, ficar junto... (Velho, 17 anos).

Para Velho, que dos treze anos aos quinze anos ganhou a vida lavando carros, a firma é lugar de mútua solidariedade, onde se está "um do lado do outro", onde se está preparado para "ajudar no que der e vier" e, sobretudo, uma forma de "ficar junto". Em linha semelhante, no depoimento de Tuti, que ajudava a família no morro do Chapadão catando latinha, vendendo bala e lavando carros, a firma sobressai como um lugar de identidade coletiva, cultivada desde a tenra infância:

\footnotetext{
P: Pra você o Comando Vermelho é mais um emprego ou uma família?

R: Uma família.

P: Por quê?

$\mathrm{R}$ : Eu sou desde molequinho, já andei já e como, me amarro mesmo. (Tuti, 15 anos).
}

Por outro lado, nos casos em que o jovem considera a firma como um simples traba- 
lho, seu discurso se apresentava na forma de uma decepção com o projeto coletivo do tráfico, reforçando a importância desta dimensão na vida dos operários da firma. Dessa maneira, esta seria um mero trabalho não só porque nela o jovem ganha dinheiro, mas também porque estão ausentes requisitos imateriais, como solidariedade e identidade, que o definiriam como "família". Sem estes, resta apenas a instrumentalização da firma como estratégia de sobrevivência material, como narra o adolescente Brabo, que antes de se tornar vapor estudava durante o dia, trabalhava em um lava-jato de tarde e roubava de noite:

P: Você via a boca como um trabalho ou como uma família?

R: Ah, é tipo um trabalho. Lá na boca tu não pode confiar nos outros moleque não. Tu tem que ter maldade com eles e eles têm maldade contigo (...) aí vamos supor, nós dois é da boca, eu vejo que tu tá se levantando, eu falo com os cara que você tá bá, não sei o quê, pra tentar te diminuir.

P: Você acha que tem muita inveja nesse meio?

$\mathrm{R}$ : Tem, é vários. Toda boca de fumo é assim. (Brabo, 17 anos).

Com raríssimas exceções, os adolescentes que entrevistei ao longo de uma década de pesquisa de campo eram todos trabalhadores natos. Versáteis e incansáveis, desde a mais tenra idade foram socializados no mundo do trabalho precário, sacrificando a escola e as brincadeiras de criança para catar latinha, juntar papelão, carregar entulho, lavar carros, guardar vagas, vender bala no trem, vender cerveja na praia, fazer carreto, trabalhar como cobrador de van, atendendo em bares, padarias, em bancas de jornal, ensacando compras de supermercado, engraxando sapatos, dando duro como assistente de pedreiro, carregando caixotes, distribuindo panfletos, entre outras incontáveis funções de muito suor e ganho escasso.

Pouco se fala sobre isso, mas a bifurcação que se apresenta na vida desses adolescentes, separando-os do futuro idealizado para toda criança, não é o crime, mas o trabalho. É pela necessidade precoce de trabalhar para complementar a renda da família que a desestruturação de seus projetos de vida começa, pavimentando o caminho para sacrifícios futuros ainda maiores, como, por exemplo, o envolvimento com o tráfico local. Não é preciso nenhum malabarismo moral para reconhecer que a firma é uma oportunidade e tanto no contexto de trajetórias como as dos garotos em questão. Há quem circunscreva sua vantagem ao caráter mais óbvio do dinheiro, ignorando ganhos imateriais que não são poucos.

Em primeiro lugar, é o primeiro trabalho potencialmente estável que encontram. Um trabalho também de caráter eminentemente doméstico, no sentido de que geralmente é realizado dentro dos territórios onde são nascidos e criados, e executado ao lado de rostos conhecidos, como vizinhos, amigos da escola e parentes. Na firma, a sensação de subalternidade absoluta experimentada em outras atividades, cede espaço à ideia de uma gradativa ascensão pelo talen- 
to, intrepidez e comprometimento - algo raro quando, por exemplo, ganha-se a vida engraxando sapatos. Uma vaga na firma também aumenta o status social no mundo de horizontes restritos da favela. É a porta de entrada para uma classe dirigente, que determina os rumos da vida de um grupo grande de pessoas.

Ao fazer parte dessa casta local, o jovem também alimenta ideias sobre sua importância, não raro se projetando como protetor e padroeiro de sua comunidade. Paralelamente, sua grandiosidade individual convive com a ideia de pertencimento a algo muito maior que ele no plano coletivo - a facção. Entretanto, positivar as atividades no tráfico de drogas como um trabalho, do qual se extrai profundo senso de valor pessoal e coletivo, só é possível à luz do mundo imaginado por esses adolescentes. Pragmaticamente, o tráfico de drogas se difere de quase todas as funções remuneradas que conhecemos. Não porque seja um crime, como muitos poderiam pensar, mas por refletir o sistema capitalista em seu estado mais puro e indomável, constituindo um mercado no qual esses jovens, oscilando entre a morte e a privação de liberdade, vendem aos "patrões" não sua força de trabalho, mas a própria energia vital.

\section{REFERÊNCIAS}

1. BATISTA, Liniker Giamarim. A grande cidade e a vida no crime: uma etnografia dos mercados do crime em uma periferia de São Paulo. 2014. Dissertação (Mestrado em Antropologia Social) - Programa de Pós-graduação em Antropologia Social, Universidade Estadual de Campinas, Campinas.

2. BARBOSA, Antonio Carlos Rafael. Um abraço para todos os amigos: algumas considerações sobre o tráfico de drogas no Rio de Janeiro. Niteró: EdUFF, 1998.

3. BARBOSA, Antonio Carlos Rafael. O Baile e a Prisão: onde se juntam as pontas dos segmentos locais que respondem pela dinâmica do tráfico de drogas no Rio de Janeiro. Cadernos de Ciências Humanas - Especiaria, v. 9, n. 15, p. 119-135, 2006. Disponível em: https://app.uff.br/riuff/handle/1/12163. Acesso em 03 mar. 2020.

4. BIONDI, Karina. Junto e misturado: uma etnografia do PCC. São Paulo: Terceiro Nome, 2010.

5. CABISTANI, L. G. Trabalho infantil e tráfico de drogas: uma análise sobre a atuação da Procuradoria Regional do Trabalho da 4a Região. 2017. Trabalho de Conclusão de Curso (Graduação em Direito) - Faculdade de Direito da Universidade Federal do Rio Grande do Sul, Porto Alegre.

6. COSTA, Elaine C. P. Amor bandido: as teias afetivas que envolvem a mulher no tráfico 
de drogas. Maceió: EdUFAL, 2008.

7. CUNHA, Christina Vital da. "Traficantes evangélicos": novas formas de experimentação do sagrado em favelas cariocas. Plural - Revista de Ciências Sociais, [S. 1.], v. 15, p. 13-46, 2008. Disponível em: http://www.revistas.usp.br/plural /article/view/75226. Acesso em: 02 fev. 2020.

8. ELIAS, Norbert. Os Estabelecidos e os Outsiders. Rio de Janeiro: Jorge Zahar, 2000.

9. FACINA, A.; PALOMBINI, C. O Patrão e a Padroeira: festas populares, criminalização e sobrevivências na Penha, Rio de Janeiro. In: MATTOS, Hebe (Org.). História oral e comunidade: reparações e culturas negras. São Paulo: Letra e Voz, 2016, p. 113-137.

10. FAU, R. Características gerais do grupo durante a adolescência. In: BRITTO, S. (Org.). Sociologia da juventude III: a vida coletiva juvenil. Rio de Janeiro: Zahar, 1968, p. 43-46.

11. FELTRAN, Gabriel de Santis. Trabalhadores e bandidos: categorias de nomeação, significados políticos. Tematicas, v. 15, n. 30, p 11- 50, 2007. Disponível em: https:// econtents.bc.unicamp.br/inpec/index.php/tematicas/article/view/13649. Acesso em: 20 jan. 2020.

12. FELTRAN, Gabriel de Santis. Fronteiras da tensão: política e violência nas periferias de São Paulo. São Paulo: Editora da Unesp, 2011.

13. FOOTE-WHYTE, William. Sociedade de Esquina. Rio de Janeiro: Zahar, 2005.

14. FREITAS, Amílcar Cardoso Vilaça de; COSTA, Elizardo Scarpati. Trabalhar e não ser trabalhador: pertencimento e reconhecimento de classe na "vida do crime". Revista Direito GV, n. 14, n. 3, p. 937-957, 2018. https: https://www.scielo.br/scielo.php?pid $=\mathrm{S} 1808-24322018000300937 \&$ script $=$ sci_abstract\&tlng=pt. Acesso em: 11 mar. 2020

15. GALDEANO, Ana Paula. Tráfico de drogas entre as piores formas de trabalho infantil: mercado, famílias e redes de proteção social. São Paulo: CEBRAP, 2018.

16. GRILLO, Carolina C. Coisas da vida no crime: tráfico e roubo em favelas cariocas. Rio de Janeiro. 2013. Tese (Doutorado em Sociologia e Antropologia) - Programa de Pós-Graduação em Sociologia e Antropologia, Universidade Federal do Rio de Janeiro, Rio de Janeiro.

17. HIRATA, Daniel Veloso. Sobreviver na adversidade: entre o mercado e a vida. São Paulo. 2010. Tese (Doutorado em Sociologa) - Programa de Pós-Graduação em Sociologia, Faculdade de Filosofia e Ciências Sociais, Universidade de São Paulo, São Paulo.

18. HIRATA, D.; GRILLO, C. Sintonia e amizade entre patrões e donos de morro: perspectivas comparativas entre o comércio varejista de drogas em São Paulo e no Rio de Janeiro. Tempo Social, n. 9, v. 2, 75-97, 2017. Disponível em: https://www.scielo. br/scielo.php?script=sci_arttext\&pid=S0103-20702017000200075. Acesso em: 03 mar. 
2020.

19. JOHNSON, Bruce et al., "Emerging models of crack distribution". In: MIECZKOWISKI, Tom (Org.). Drug, crime and social policy: research, issues and concerns. Boston: Ally and Bacon, 1992.

20. LEITE, Márcia Pereira. Violência, insegurança e cidadania: reflexões a partir do Rio de Janeiro. Observatório da Cidadania, Rio de Janeiro p. 66-70, 2005. Disponível em: https://www.socialwatch.org/sites/default/files/pdf/en/panorbrasileiroe2005_bra.p df. Acesso em: 02 fev. 2020.

21. LYRA, Diogo. A República dos Meninos: juventude, tráfico e virtude. Rio de Janeiro: Mauad X, 2013.

22. MACHADO DA SILVA. L. A. Vida sob Cerco: violência e rotinas nas favelas do Rio de Janeiro. Rio de Janeiro: Nova Fronteira, 2008.

23. MALVASI, Paulo Arthur. Interfaces da vida loka: um estudo sobre jovens, tráfico de drogas e violência em São Paulo. 2012. Tese (Doutorado em Saúde Materno Infantil) Faculdade de Saúde Pública, Universidade de São Paulo, São Paulo.

24. MARQUES, Adalton. Crime e proceder: um experimento antropológico. São Paulo, Alameda, 2014.

25. MATZA, D. Delinquency and Drift. New York: John Wiley and Sons Inc, 1964.

26. NAPOLIÃO, Paula; MENEZES, Fernanda; LYRA, Diogo. Ganhar a vida, perder a liberdade. Tráfico, trabalho e sistema socioeducativo. Boletim Segurança e Cidadania, Centro de Estudos de Segurança e Cidadania, Rio de Janeiro, n. 25, 2020. Disponível em: https://cesecseguranca.com.br/boletim/ganhar-a-vida-perder-a-liberdade-traficotrabalho-e-sistema-socioeducativo/. Acesso em: 30 jul. 2020.

27. NERI, Natasha E. O "convívio" em uma "cadeia dimenor": um olhar sobre as relações entre adolescentes internados. R@U: Revista de Antropologia Social dos Alunos do PPGAS-UFSCar, v.3, p. 315 - 330, 2011. Disponível em: https://issuu.com/raufscar/d ocs/rauv3n1. Acesso em: 03 mar. 2020.

28. ORGANIZAÇÃO INTERNACIONAL DO TRABALHO. Convenção 182, Sobre a Proibição das Piores Formas de Trabalho Infantil e a Ação Imediata para a sua Eliminação. Genebra, 1999.

29. ORGANIZAÇÃO INTERNACIONAL DO TRABALHO. Recomendação 190, Sobre a Proibição e Ação Imediata para a Eliminação das Piores Formas de Trabalho Infantil. Genebra, 1999.

30. ORTIZ, Didier Correia. Narc Deco: ética y estética del Narcotráfico. Analecta Política, Medelín, v. 2, n. 03. p. 127-140, 2012. Disponível em: https://revistas.upb.edu.co/index. php/analecta/article/view/2991. Acesso em: 02 fev. 2020. 
31. PARSONS, T. A classe como sistema social. In: BRITTO, S. (Org.). Sociologia da juventude III: a vida coletiva juvenil. Rio de Janeiro: Zahar, 1968, p. 47-76.

32. RINCÓN, Omar. Todos temos um pouco do tráfico dentro de nós: um ensaio sobre o narcotráfico/cultura/novela como modo de entrada para a modernidade. Matrizes, São Paulo, ano, 7 n. 2, p. 193-219, 2013. Disponível em: https:/www.revistas.usp.br/ matrizes/article/view/69414. Acesso em: 17 jan. 2020.

33. SILVA. Luís Antonio Machado. Vida sob Cerco: violência e rotinas nas favelas do Rio de Janeiro. Rio de Janeiro: Nova Fronteira, 2008.

34. ZALUAR, Alba. A máquina e a Revolta. São Paulo: Brasiliense, 1985.

35. ZALUAR, Alba. Integração Perversa: pobreza e tráfico de drogas. Rio de Janeiro: Editora FGV, 2004.

Diogo Lyra

Doutor em Sociologia pelo Instituto Universitário de Pesquisas do Rio de Janeiro. Pós-Doutorado pelo Social Science Research Council - Drugs, Security and Democracy Fellowship Program. Pós-Doutorado no Núcleo Interdisciplinar de Estudos sobre a Desigualdade do Programa de Pós-Graduação em Sociologia e Antropologia da Universidade Federal do Rio de Janeiro. ID ORCID: https://orcid.org/0000-0003-0484-5089. E-mail: dlyra77@gmail.com. 